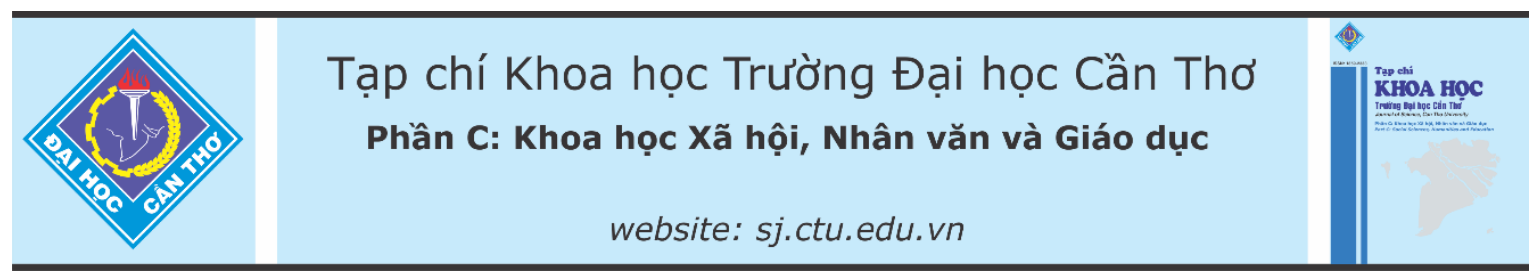

DOI:10.22144/ctu.jvn.2021.160

\title{
CÁC NHÂN TỐ ẢNH HƯởNG ĐẾN SỰ THAM GIA CỦA CỘNG ĐỒNG TRONG DU LỊCH: TRƯỜnG HỢP THÀNH PHỐ HÀ TIÊN, TỈNH KIÊN GIANG
}

\author{
Nguyễn Trọng Nhân ${ }^{1 *}$ và Trương Trí Thông ${ }^{2}$ \\ ${ }^{1}$ Khoa Khoa họ xã hội và Nhân văn, Truờng Đại học Cần Tho' \\ ${ }^{2}$ Khoa Du lịch, Truờng Cao đẳng Kiên Giang \\ *Nguời chịu trách nhiệm về bài viết: Nguyễn Trọng Nhân (email: trongnhan@ctu.edu.vn)
}

\section{Thông tin chung:}

Ngày nhận bài: $27 / 11 / 2020$

Ngày nhận bài sủa: 23/12/2020

Ngày duyệt đăng: 29/10/2021

\section{Title:}

Factors influencing community participation in tourism: The case of Ha Tien city, Kien Giang province

\section{Tù khóa:}

Du lịch cộng đồng, sự tham gia trong du lịch, thành phố Hà Tiên, tỉnh Kiên Giang

\section{Keywords:}

Community-based tourism, $\mathrm{Ha}$ Tien city, Kien Giang province, tourism participation

\begin{abstract}
Community is one of the subjects to ensure the sustainable development of a destination. Ha Tien city, Kien Giang province has identified communitybased tourism development as a suitable direction in the future. This research was done to clarify the factors affecting the participation in tourism of the community, then provide local evidence in implementing solutions to attract community participation in tourism. Study data were collected from 100 respondents via questionnaire interview. Descriptive statistics and $\chi^{2}$ test were used to analyze the data. The research results show that there are 9 factors affecting the participation of the community in tourism (tourism skills, confidence to do tourism, desire to participate in tourism, tourism interests, family encouragement, opportunities to participate in tourism, traditional occupation ownership, perception towards the advantages of the tourism industry, local attraction policies). In order to attract more community participation in tourism, the locality should promote education and tourism development, widely provide coverage on the importance of the tourism industry, at the same time create favorable conditions for people to participate in tourism.
\end{abstract}

\section{TÓM TẮT}

Cộng đồng là một trong nhũng chủ thể đảm bảo sự phát triển bền vũng của điểm đến. Thành phố Hà Tiên (tỉnh Kiên Giang) đã xác định phát triển du lịch dự vào cộng đồng là hướng đi phù hợp ở tuoong lai. Nghiên cứu này được thực hiện nhằm làm sáng tỏ các nhân tố ảnh hưởng đến sự tham gia trong $d u$ lịch của công đồng, đồng thời, cung cấp luận cư cho địa phương trong việc thực thi các giải pháp thu hút sụ tham gia của công đồng trong du lịch. Dũ liệu của nghiên cưu được thu thập tù phỏng vấn 100 đáp viên bằng bảng hỏi. Thống kê mô tả và kiểm định $\chi^{2}$ được sư dụng để phân tích dũ liệu. Kểt quả nghiên cứu cho thấy có 9 nhân tố ảnh hưởng đến sự tham gia của cộng đồng trong du lịch (kỹ năng làm du lịch, sụ tự tin để làm du lịch, mong muốn tham gia làm du lịch, sở thich làm du lịch, sụ cổ vũ của gia đình, co hộ tham gia du lịch, sở hưu nghề truyền thống, cảm nhận lợi thể của ngành du lịch, chính sách thu hút của địa phưong). Để thu hút sự tham gia hơn nũ̃a của công đồng trong du lịch, địa phuoong nên đẩy mạnh phát triển giáo dục và du lịch, thông tin rộng rãi về tầm quan trọng của ngành du lịch, đồng thời tạo điều kiện thuận lợi để người dân tham gia làm du lịch. 


\section{GIỚI THIẸU}

Du lịch là lĩnh vực lớn nhất và phát triển nhanh nhất của nền kinh tế toàn cầu. Sự phát triển của ngành du lịch tạo ra doanh thu và việc làm lớn hơn so với nhiều ngành kinh tế khác của thế giới (Eagles et al., 2001). Vì lẽ đó, du lịch đã trở thành một trong những ngành kinh tế quan trọng của nhiều nước công nghiệp phát triển và được coi là cứu cánh để vực dậy nền kinh tế ốm yếu của các quốc gia đang phát triển (Trần Đức Thanh, 2003). Nhận thức được tầm quan trọng của du lịch, năm 2017, Bộ Chính trị đưa ra Nghị quyết $08-\mathrm{NQ} / \mathrm{TW}$ về phát triển du lịch trở thành ngành kinh tế mũi nhọn. Từ đó, nhiều địa phương trên cả nước cũng xác định du lịch là ngành kinh tế mũi nhọn và tích cực xây dựng kế hoạch hành động để đưa Nghị quyết $08-\mathrm{NQ} / \mathrm{TW}$ của Bộ Chính trị vào cuộc sống, trong đó có thành phố Hà Tiên (Hoàng Giám, 2019).

Sự tham gia của cộng đồng trong du lịch là rất cần thiết bởi những nhu cầu của du khách có thể được đáp ứng nhờ vào cộng đồng, hơn nữa, gặp gõ và được phục vụ bởi cộng đồng là động cơ du lịch của nhiều du khách. Ngoài ra, ngành du lịch sử dụng nhiều nguồn lực và có thể gây ra những tác động tiêu cực đối với cộng đồng. Sự tham gia của cộng đồng trong du lịch mang lại lợi ích to lớn cho nhiều bên liên quan (cộng đồng có việc làm, thu nhập ổn định và nâng cao năng lực kinh doanh; điểm đển duy trì được sức hấp dẫn và đa dạng hóa dịch vụ; doanh nghiệp bán được tour du lịch và cải thiện sức mua của khách hàng; du khách có được những trải nghiệm thú vị và có thể mua được hàng hóa, dịch vụ với mức giá hợp lý hơn). Vì lẽ đó, sự thành công của du lịch phụ thuộc vào sự hỗ trợ tích cực của cộng đồng, nếu không có sự tham gia của cộng đồng, sự bền vững của ngành du lịch bị đe dọa (Joobi \& Satheesh, 2017).

Thành phố Hà Tiên nằm ở phía tây bắc của tỉnh Kiên Giang với diện tích 100,49 km², dân số 48.495 người (2019). Thành phố Hà Tiên giàu có về thắng cảnh (quần đảo Hải Tặc, đầm Đông Hồ, núi Bình San, Thạch Động, núi Đá Dựng, mũi Nai), di tích lịch sử - văn hóa (nhà tù Hà Tiên, Bình San, chùa Phù Dung, chùa Tam Bảo, chùa Xà Xía, đình thần Thành Hoàng,...), lễ hội (Tao đàn Chiêu Anh Các, Kỳ Yên, lễ giỗ Đức khai trấn Mạc Cửu,...); là đầu mối giao thông, giao thương đường bộ với Campuchia, Thái Lan và nhiều nước Đông Nam Á khác (cửa khẩu quốc tế Hà Tiên, cửa khẩu quốc gia Giang Thành, đường xuyên Á,...); có hệ thống cơ sở hạ tầng tương đối đồng bộ;....nên rất thuận lợi để phát triển du lịch. Trong các đơn vị hành chính của tỉnh Kiên Giang, thành phố Hà Tiên có số lượt khách và doanh thu dịch vụ du lịch chỉ đứng sau huyện Phú Quốc (Hoàng Giám, 2019). Năm 2018, Hà Tiên đón trên 2,5 triệu lượt khách, doanh thu dịch vụ du lịch đạt hơn 1.400 tỷ đồng (Thiện Kỳ, 2019). Đặc biệt, trong năm 2020, chính quyền đô thị Hà Tiển khẩn trương đẩy nhanh tiến độ đầu tư, xây dựng nâng cấp nhiều điểm du lịch, chỉnh trang nhiều khu đô thị, nâng cấp hệ thống giao thông, thiết lập hệ thống điện chiếu sáng công cộng, trồng thêm cây xanh,... để tạo đà cho sự phát triển du lịch mạnh hơn trong những năm tới (Huy Thịnh, 2020). Theo Huy Thịnh (2020), để tạo đột phá cho sự phát triển du lịch của Hà Tiên, địa phương cần giữ được sự hoang sơ thuần khiết của cảnh quan biển đảo; kết hợp với nhà đầu tư chuyên nghiệp tạo ra những điểm du lịch nghỉ dưỡng, khám phá và giải trí biển phù hợp; phát triển nguồn nhân lực du lịch chuyên sâu; phát triển du lịch cộng đồng.

Thành phố Hà Tiên sẽ bảo tồn cảnh quan và tài nguyên du lịch, phát triển loại hình và dịch vụ du lịch tốt hơn khi có sự tham gia sâu rộng và hưởng lợi của cộng đồng trong quá trình phát triển du lịch. Một số học giả trên thế giới cho rằng khi cộng đồng được tham gia và hưởng lợi từ du lịch, họ thường cố gắng hết sức để bảo vệ tài nguyên, môi trường $\mathrm{du}$ lịch (Lacy et al., 2002, trích dẫn bởi Aref, 2011), tích cực cung cấp các yếu tố vật chất và dịch vụ cho sự phát triển du lịch (Godfrey \& Clarke, 2000, trích dẫn bởi Mustapha et al., 2013). Hơn nữa, chỉ có thể phát triển du lịch cộng đồng khi có sự tham gia của họ. Đào Ngọc Cảnh và Nguyễn Kim Hồng (2017) cũng cho rằng thành phố Hà Tiên cần có chính sách khuyến khích người dân và doanh nghiệp tham gia làm du lịch.

Nghiên cứu này được thực hiện nhằm phân tích các nhân tố ảnh hưởng đến sự tham gia của cộng đồng trong du lịch, qua đó, cung cấp bằng chứng cho thành phố Hà Tiên nói riêng, nhiều điểm đến khác ở Việt Nam nói chung trong việc thực thi các giải pháp nhằm thu hút sự tham gia sâu rộng của cộng đồng trong du lịch - đảm bảo sự phát triển du lịch nhanh và bền vững.

\section{PHƯƠNG PHÁP NGHIÊN CÚU}

\subsection{Cơ sở lý thuyết và mô hình nghiên cứu}

Đến nay, vẫn chưa có sự thống nhất nhận thức về cộng đồng giữa các học giả. Từ việc tổng quan 94 định nghĩa về cộng đồng, Hillery (1995, trích dẫn bởi Alshboul, 2016) đưa ra 3 khía cạnh chính liên quan đến cộng đồng: (i) khu vực, (2) mối quan tâm chung, (3) tương tác xã hội. Dưới góc độ khu vực, Jamal and Getz (1995, trích dẫn bởi Alshboul, 2016) 
cho rằng, cộng đồng là một nhóm người sinh sống trong cùng vị trí. Tiếp cận cộng đồng ở góc độ khu vực và mối quan tâm chung, Aref et al. (2010) chỉ rõ cộng đồng là một nhóm người đang sinh sống và làm việc trong cùng khu vực địa lí với cùng nền văn hóa hoặc mối quan tâm chung. Xem xét cộng đồng ở phương diện tương tác xã hội và khu vực, Johnston (2000) khẳng định, cộng đồng là một mạng lưới xã hội tương tác cá nhân, tập trung ở một lãnh thổ xác định. Như vậy, có thể hiêu cộng đồng là một nhóm người đang sinh sống, làm việc và tương tác với nhau trong cùng khu vực địa lý (ấp, xã, huyện,...).

Thật khó để thiết lập một định nghĩa vững chắc mang tính toàn cầu về sự tham gia của cộng đồng trong du lịch, vì vậy, mỗi nhà nghiên cứu nên xác định và giải thích thuật ngữ sự tham gia của cộng đồng trong du lịch thích hợp với nghiên cứu của mình và thỏa mãn mục tiêu cụ thể đã xác định (Mak, 2011). Đối với nghiên cứu này, sự tham gia của cộng đồng trong du lịch được hiểu là cộng đồng ở các đơn vị hành chính khác nhau với mức độ phát triển du lịch khác nhau tham gia vào quá trình phát triển du lịch như xác định loại hình và dịch vụ du lịch, quy mô phát triển du lịch, cơ chế chia sẻ lợi ích từ du lịch và cung ứng các dịch vụ du lịch, quản lý và vận hành sự phát triển du lịch ở địa phương của họ.

Có nhiều nhân tố ảnh hưởng đến sự tham gia của cộng đồng trong du lịch, chẳng hạn, lợi ích so sánh của ngành công nghiệp du lịch, mong muốn chủ quan của người tham gia, nhận thức đạt được cơ hội tham gia trong kinh doanh du lịch, kỹ năng của người tham gia (Shui et al., 2012). Nguyễn Quốc Nghi và ctv. (2012) lại cho rằng sự tham gia của cộng đồng trong du lịch chịu tác động bởi trình độ học vấn của chủ hộ, quy mô gia đình, thu nhập của gia đình, vốn xã hội, nghề truyền thống. Nghiên cứu của Salleh et al. (2016) cho thấy 5 nhân tố ảnh hưởng đến sự tham gia của cộng đồng trong du lịch là sự cổ vũ của gia đình, sở thích cá nhân, sự tự tin vào bản thân, cơ hội việc làm, thu nhập. Trong khi đó, Đỗ Thiện Toàn và ctv. (2016) khẳng định chính sách của địa phương, môi trường tự nhiên và vốn xã hội, văn hóa xã hội, nguồn lực địa phương, lợi ích kinh tế ảnh hưởng đến sự tham gia của cộng đồng trong du lịch. Kết quả nghiên cứu của Mugizi et al. (2017) chỉ rõ trình độ giáo dục, sự tham gia lao động trong nông nghiệp, sự cung cấp dịch vụ cho du khách, thu nhập, sở hữu đất đai ảnh hưởng đến sự tham gia của cộng đồng trong du lịch. Những nhân tố khác ảnh hường đến sự tham gia của cộng đồng trong du lịch là lãnh đạo của địa phương, cảm nhận lợi ích có được từ du lịch của cộng đồng, khả năng tiếp cận/vị trí, cơ hội việc làm trong lĩnh vực công và tư (Ekwale, 2014), sự biểu biết cụ thể của cộng đồng về dự án phát triển du lịch (Briedenhan \& Wickens, 2004, trích dẫn bởi Ekwale, 2014), giới tính, tuổi của người dân (Dolisca et al., 2006, trích dẫn bởi Ekwale, 2014).

Trên cơ sở tổng quan các nhân tố ảnh hưởng đến sự tham gia của cộng đồng trong du lịch đã được đề cập, nhóm nghiên cứu đề xuất mô hình nghiên cứu của đề tài như sau:

\begin{tabular}{|l|l|}
\hline Giới tính \\
\hline Số người trong gia đình \\
\hline Trình độ học vấn/chuyên môn \\
\hline Sở hữu đất đai \\
\hline Kở hữu nghề truyền thống trung bình/tháng làm du lịch \\
\hline Quan hệ xã hội
\end{tabular}

Hình 1. Mô hình nghiên cứu

(Nguồn: Nhóm nghiên cúu, 2020) 
Kết quả mong đợi của nghiên cứu như sau:

Có sự khác biệt có ý nghĩa thống kê về thực trạng tham gia của cộng đồng trong du lịch theo giới tính, số người trong gia đình, trình độ học vấn/chuyên môn, thu nhập trung bình/tháng, sở hữu đất đai, sở hữu nghề truyền thống, kỹ năng làm du lịch, quan hệ xã hội, sự tự tin, mong muốn tham gia làm du lịch, sở thích tham gia làm du lịch, sự cổ vũ của gia đình, lợi thế so sánh của ngành du lịch, chính sách thu hút của địa phương, cơ hội tham gia làm du lịch, nắm bắt thông tin về dự án phát triển du lịch.

\subsection{Phương pháp nghiên cứu}

Nghiên cứu này nhằm làm rõ các nhân tố ảnh hưởng đến sự tham gia và chưa tham gia trong $\mathrm{du}$ lịch của cộng đồng ở thành phố Hà Tiên. Vì lẽ đó, dữ liệu chính của nghiên cứu được thu thập từ phỏng vấn 100 người dân địa phương (49 người tham gia và 51 người chưa tham gia du lịch) bằng bảng hỏi. Cấu trúc của bảng hỏi gồm 4 phần: phần 1 có 5 câu hỏi về thông tin cá nhân của đáp viên; phần 2 có 6 câu hỏi về các rào cản đối với sự tham gia của cộng đồng trong du lịch; 16 câu hỏi về các nhân tố ảnh hưởng đến sự tham gia của cộng đồng trong du lịch được thiết kế ở phần 3; 8 câu hỏi về thực trạng tham gia trong du lịch của cộng đồng được thiết kế ở phần 4. Các câu hỏi thuộc dạng đóng, mở và được đo lường bởi thang định danh, thứ bậc, tỉ lệ. Đối với phần nội dung chính của nghiên cứu này, các biến độc lập được đo lường như sau:

\section{Bảng 1. Diễn giải biến độc lập}

\begin{tabular}{|c|c|c|}
\hline Biến độc lập & Diễn giải & Nguồn tham khảo \\
\hline Giới tính & (1) Nam (2)Nữ & $\begin{array}{l}\text { Dolisca et al. (2006, trích dẫn bởi } \\
\text { Ekwale, 2014) }\end{array}$ \\
\hline Số người trong gia đình & (1) 1-3 người (2) 4-8 người & Nguyễn Quốc Nghi và ctv. (2012) \\
\hline Trình độ học vấn, chuyên môn & (1) $\leq$ THPT (2) Trên THPT & Nguyễn Quốc Nghi và ctv. (2012) \\
\hline Thu nhập trung bình/tháng & (1) 0-12 triệu (2) 13-150 triệu & Nguyễn Quốc Nghi và ctv. (2012) \\
\hline Sở hữu đất đai & (1) $0-110 \mathrm{~m}^{2}$ (2) $120-50.000 \mathrm{~m}^{2}$ & Mugizi et al. (2017) \\
\hline Sở hữu nghề truyền thống & (1) Không (2) Có & Nguyễn Quốc Nghi và ctv. (2012) \\
\hline Kỹ năng làm du lịch & (1) Không (2) Có & Shui et al. (2012) \\
\hline Quan hệ xã hội & (1) Hạn chế (2) Rộng & Nguyễn Quốc Nghi và ctv. (2012) \\
\hline Sự tự tin & (1) Không (2) Có & Salleh et al. (2016) \\
\hline Mong muốn tham gia du lịch & (1) Không (2) Có & Shui et al. (2012) \\
\hline Sở thích làm du lịch & (1) Không (2) Có & Salleh et al. (2016) \\
\hline Sự cổ vũ của gia đình & (1) Không (2) Có & Salleh et al. (2016) \\
\hline Lợi thế so sánh của ngành du lịch & (1) Kém hơn (2) Tốt hơn & Shui et al. (2012) \\
\hline Chính sách thu hút của địa phương & (1) Không (2) Có & Đỗ Thiện Toàn và ctv. (2016) \\
\hline Cơ hội tham gia du lịch & (1) Không (2) Có & Shui et al. (2012) \\
\hline Nắm bắt thông tin về dự án du lịch & hông (2) Có & $\begin{array}{l}\text { Briedenhan and Wickens (2004, trích } \\
\text { dẫn bởi Ekwale, 2014) }\end{array}$ \\
\hline
\end{tabular}

Ghi chú: Biến có 2 lựa chọn dạng định danh và thứ bậc phù hợp với phân tích Chi-bình phuơng $\left(\chi^{2}\right)$ đồng thời đảm bảo sụ rõ ràng của các phương án trả lò̀i.

(Nguồn: Nhóm nghiên cúu, 2020)

Đáp viên của nghiên cứu được chọn bằng kỹ thuật lấy mẫu kiểu thuận tiện. Địa điểm phỏng vấn gồm núi Bình San, Thạch Động và Mũi Nai. Thời gian phỏng vấn từ 17/10/2019-14/3/2020. Dữ liệu phỏng vấn được phân tích dưới dạng thống kê mô tả (\%, giá trị trung bình) và kiểm định Chi-bình phương.

\section{KẾT QUẢ VÀ THẢO LUẬN}

\subsection{Khái quát mẫu nghiên cứu}

Để làm sáng tỏ các nhân tố ảnh hưởng đến sự tham gia của cộng đồng trong du lịch ở thành phố
Hà Tiên, 100 người dân địa phương được phỏng vấn ở 3 địa điểm núi Bình San (17 người), Thạch Động (30 người) và Mũi Nai (53 người). Trong đó, 49 người đang tham gia và 51 người chưa tham gia trong ngành du lịch, đại diện cho nhóm thực nghiệm và nhóm đối chứng. Về giới tính, có 51 người nữ, và 49 người nam tham gia cuộc phỏng vấn, chiếm $51 \%$ và $49 \%$, lần lượt. Độ tuổi của mẫu nghiên cứu thấp nhất là 20 , cao nhất là 62 , trung bình là 33,3 tuổi. Mẫu nghiên cứu chủ yếu là người Kinh (90 người); người Khmer (6) và người Hoa (4) ít được chọn để phỏng vấn. 
Bảng 2. Đặc điểm mẫu nghiên cứu $(\mathrm{n}=100)$

\begin{tabular}{llcllc}
\hline Biến & Diễn giải & Phần trăm & Biến & Diễn giải & Phần trăm \\
\hline \multirow{3}{*}{ Địa điểm } & Núi Bình San & 17 & \multirow{2}{*}{ Dân tộc } & Kinh & 90 \\
& Thạch Động & 30 & Khmer & 6 \\
& Mũi Nai & 53 & & Hoa & 4 \\
\hline \multirow{2}{*}{ Thực trạng tham gia du lịch } & Đang tham gia & 49 & \multirow{2}{*}{ Giới tính } & Nam & 49 \\
& Chưa tham gia & 51 & \multirow{2}{*}{ Nư } & 51 \\
\hline
\end{tabular}

(Nguồn: Kết quả phân tích dũ liệu phỏng vấn của nhóm nghiên cưu, 2020)

\subsection{Thưc trang tham gia trong du lich của cộng đồng (trường hợp mẫu nghiên cứu) ở thành phố Hà Tiên}

Mẫu khảo sát có thời gian tham gia trong du lịch thấp nhất là 1 năm, cao nhất là 15 năm và trung bình là 5,3 năm. Họ tham gia trong du lịch vì muốn có việc làm và thu nhập ổn định. Một số người tham gia trong du lịch còn vì sở thích, niềm đam mê kinh doanh/hoạt động trong lĩnh vực du lịch. Bên cạnh đó, làm việc đúng chuyên ngành đào tạo cũng là một trong những nguyên nhân dẫn đến sự tham gia trong $\mathrm{du}$ lịch của cộng đồng. Để có thể tham gia trong du lịch, nhiều người cho rằng họ phải kiến thức, kỹ năng và kinh nghiệm làm du lịch. Bên cạnh đó, không ít người trả lời vốn và chứng chỉ/bằng cấp chuyên môn là điều kiện cần thiết để họ tham gia trong du lịch. Ngoài ra, sở thích/niềm đam mê kinh doanh/làm việc trong lĩnh vực du lịch, khả năng quan hệ xã hội và ăn nói, năng lực ngoại ngữ, sức khỏe cũng là những điều kiện quan trọng để đáp viên có thể đến với ngành/nghề du lịch. Cộng đồng ở thành phố Hà Tiên tham gia trong nhiều hoạt động liên quan đến ngành du lịch nhưng điển hình là phục vụ/tổ chức ăn uống, lưu trú, mua sắm, tham quan, đi lại và giải trí của du khách. Tham gia trong du lịch, người dân có được việc làm và thu nhập ổn định; chất lượng cuộc sống của họ cũng được nâng cao. Hơn nữa, kiến thức, kỹ năng và kinh nghiệm về du lịch được tích lũy trong quá trình tham gia của họ trong du lịch. Một số người còn cho rằng, nhờ vào du lịch, họ có thể thiết lập, mở rộng mối quan hệ xã hội và cải thiện năng lực giao tiếp của bản thân.

Sự tham gia của cộng đồng trong du lịch chủ yếu diễn ra ở thắng cảnh Núi Đá Dựng, Mũi Nai, Thạch Động, Đầm Đông Hồ, Núi Bình San, Chùa Phù Dung và phụ cận. Đặc biệt, trung tâm của thành phố Hà Tiên là nơi quy tụ rất nhiều người dân, doanh nghiệp, hướng dẫn viên, nhân viên phục vụ trong lĩnh vực du lịch. Trong những năm gần đây, chính quyền thành phố Hà Tiên quan tâm phát triển du lịch cộng đồng xã đảo Tiên Hải, nhờ đó, mở rộng không gian du lịch cộng đồng và tạo cơ hội cho sự tham gia của cộng đồng trong du lịch. Để tạo điều kiện thuận lợi cho sự phát triển du lịch cộng đồng ở địa phương, chính quyền đô thị Hà Tiên đã mở lớp tập huấn, bồi dưỡng kiến thức, kỹ năng liên quan đến hoạt động quản lý, kinh doanh, phục vụ, giao tiếp, thuyết minh trong du lịch cho nhiều người dân; trang bị kiến thức về bảo vệ môi trường và đảm bảo an toàn trong du lịch cho người dân (Lê Huy Hải, 2017); kêu gọi các thành phần kinh tế đầu tư các khu vui chơi giải trí, xây dựng cở hạ tầng kỹ thuật, xây dựng sản phẩm du lịch đặc trưng,... Sự tham gia của cộng đồng trong du lịch đã và đang tạo động lực cho sự phát triển kinh tế - xã hội, nâng cao đời sống vật chất và tinh thần cho người dân nói riêng và địa phương nói chung, đặc biệt góp phần bảo vệ vững chắc biên giới và hải đảo vùng Tây Nam của đất nước (Việt Tiến, 2018).

\subsection{Các nhân tố ảnh hưởng đến sự tham gia của cộng đồng trong du lịch ở thành phố Hà Tiên}

Có thể có sự khác biệt có ý nghĩa thống kê giữa nhóm tham gia và chưa tham gia trong du lịch theo các khía cạnh được thể hiện ở mô hình nghiên cứu (Hình 1). Thực tế này đã được chứng minh bởi nhiều học giả được thể hiện ở Bảng 1. Tuy nhiên, cỡ mẫu, kỹ thuật chọn mẫu, tỷ lệ giữa hai nhóm, thang đo, kỹ thuật phân tích dữ liệu, địa phương, quốc gia khác nhau,... có thể cho ra kết quả khác nhau. Vì vậy, những cố gắng đối với nghiên cứu này nhằm kiểm định lại kết quả của nhiều nghiên cứu liên quan đồng thời tạo ra bức tranh tương đối đầy đủ về những trở ngại đối với sự tham gia trong du lịch của cộng đồng ở thành phố Hà Tiên.

Kết quả phân tích dữ liệu cho thấy không có sự khác biệt về việc tham gia hay chưa tham gia trong du lịch của cộng đồng ở thành phố Hà Tiên theo giới tính, số người trong gia đình, trình độ học vấn/chuyên môn, thu nhập trung bình/tháng, diện tích đất sở hữu, quan hệ xã hội, sự nắm bắt thông tin về dự án phát triển du lịch. Phát hiện này khác với kết quả nghiên cứu của Dolisca et al. (2006, trích dẫn bởi Ekwale, 2014), Nguyễn Quốc Nghi và ctv. (2012), Mugizi et al. (2017), Briedenhan and Wickens (2004, trích dẫn bởi Ekwale, 2014). 
Ỏ độ tin cậy 99\%, sự tham gia hay chưa tham gia của cộng đồng trong du lịch ở thành phố Hà Tiên có khác biệt theo kỹ năng du lịch, sự tự tin trong việc kinh doanh/phục vụ du lịch, mong muốn tham gia vào du lịch, sở thích làm du lịch, sự cổ vũ của gia đình, cơ hội tham gia trong du lịch. Kết quả này phù hợp với nghiên cứu của Shui et al. (2012), Salleh et al. (2016). Hầu hết những người tham gia trong du lịch ở thành phố Hà Tiên là những người có kỹ năng du lịch, có đủ tự tin để kinh doanh và làm việc trong lĩnh vực du lịch, mong muốn tham gia vào ngành du lịch, thích làm du lịch, nhận được sự cổ vũ của gia đình và có cơ hội để tham gia vào lĩnh vực du lịch (Bảng 3). Trong khi đó, những người chưa tham gia vào du lịch ở thành phố Hà Tiên là những người có những biểu hiện hoàn toàn trái ngược với những người tham gia du lịch, tỷ lệ trả lời "không" của họ đối với các khía cạnh trên được thể hiện ở Bảng 3 .

Bảng 3. Sự khác biệt về thực trạng tham gia của cộng đồng trong du lịch ở thành phố Hà Tiên (độ tin cậy $99 \%)(n=100)$

\begin{tabular}{|c|c|c|c|c|}
\hline \multirow{2}{*}{ Biến } & \multirow{2}{*}{$\begin{array}{l}\text { Thực trạng tham gia } \\
\text { du lịch }\end{array}$} & \multicolumn{2}{|c|}{ Biểu hiện của đối tượng } & \multirow{2}{*}{ Sig. } \\
\hline & & Có (\%) & Không (\%) & \\
\hline \multirow{2}{*}{ Kỹ năng làm du lịch } & Tham gia & 47 & 2 & \multirow{12}{*}{0,000} \\
\hline & Chưa tham gia & 26 & 25 & \\
\hline \multirow{2}{*}{ Sự tự tin làm du lịch } & Tham gia & 49 & 0 & \\
\hline & Chưa tham gia & 32 & 19 & \\
\hline \multirow{2}{*}{ Mong muốn tham gia du lịch } & Tham gia & 49 & 0 & \\
\hline & Chưa tham gia & 30 & 21 & \\
\hline \multirow{2}{*}{ Sở thích làm du lịch } & Tham gia & 49 & 0 & \\
\hline & Chưa tham gia & 35 & 16 & \\
\hline \multirow{2}{*}{ Sự cổ vũ của gia đình } & Tham gia & 48 & 1 & \\
\hline & Chưa tham gia & 35 & 14 & \\
\hline \multirow{2}{*}{ Cơ hội tham gia trong du lịch } & Tham gia & 48 & 1 & \\
\hline & Chưa tham gia & 35 & 16 & \\
\hline
\end{tabular}

(Nguồn: Kết quả phân tích dũ liệu phỏng vấn của nhóm nghiên cứu, 2020)

Ở 95\% độ tin cậy, sự tham gia và chưa tham gia của cộng đồng trong du lịch ở thành phố Hà Tiên có sự khác biệt theo sở hữu nghề truyền thống, cảm nhận lợi thế của ngành du lịch so với các ngành kinh tế khác trên phương diện việc làm, thu nhập, trách nhiệm đối với môi trường và văn hóa, chính sách thu hút tham gia kinh doanh du lịch của địa phương. Kết quả này tương đồng với nghiên cứu của Nguyễn Quốc Nghi và ctv. (2012), Shui et al. (2012), Đỗ Thiện Toàn và ctv. (2016). Những người tham gia trong du lịch ở thành phố Hà Tiên là những người ít nhiều có sở hữu nghề truyền thống; cảm nhận ngành du lịch có khả năng tạo việc làm, thu nhập, trách nhiệm đối với môi trường và văn hóa tốt hơn những ngành kinh tế khác. Bên cạnh đó, nhận được sự khuyến khích tham gia trong lĩnh vực du lịch của chính quyền địa phương cũng là tiền đề quan trọng để người dân tham gia trong du lịch (Bảng 4). Những người chưa tham gia trong du lịch ở thành phố Hà Tiên là những người (hầu hết) không có nghề truyền thống; cảm nhận chưa đúng vai trò của ngành du lịch trong khả năng tạo việc làm, thu nhập, trách nhiệm đối với môi trường và văn hóa; chưa nhận được sự khuyến khích tham gia du lịch của chính quyền địa phương (Bảng 4).

Bảng 4. Sự khác biệt về thực trạng tham gia của cộng đồng trong du lịch ở thành phố Hà Tiên (độ tin cậy 95\%)

\begin{tabular}{|c|c|c|c|c|}
\hline \multirow{2}{*}{ Biến } & \multirow{2}{*}{$\begin{array}{l}\text { Thực trạng tham } \\
\text { gia du lịch }\end{array}$} & \multicolumn{2}{|c|}{ Biểu hiện của đối tượng } & \multirow{2}{*}{ Sig. } \\
\hline & & Có (\%) & Không (\%) & \\
\hline \multirow{2}{*}{ Sở hữu nghề truyền thống } & Tham gia & 7 & 42 & \multirow{6}{*}{$<0,05$} \\
\hline & Chưa tham gia & 1 & 50 & \\
\hline \multirow{2}{*}{ Cảm nhận lợi thế của ngành du lịch } & Tham gia & 47 & 2 & \\
\hline & Chưa tham gia & 43 & 8 & \\
\hline \multirow{2}{*}{ Chính sách thu hút của địa phương } & Tham gia & 39 & 10 & \\
\hline & Chưa tham gia & 30 & 21 & \\
\hline
\end{tabular}

(Nguồn: Kết quả phân tích dũ liệu phỏng vấn của nhóm nghiên cưu, 2020) 
Kết quả nghiên cứu cho thấy $9 / 16$ biến có ảnh hưởng đển sự tham gia của cộng đồng trong du lịch ở thành phố Hà Tiên, đạt 56,3\% mô hình kỳ vọng. Bảy biến không ảnh hưởng đến sự tham gia trong du lịch của cộng đồng ở thành phố Hà Tiên $(43,7 \%)$ liên quan đến giới tính, quy mô gia đình, trình độ, thu nhập, sở hữu đất đai, quan hệ xã hội, khả năng nắm bắt thông tin phát triển du lịch của cộng đồng. Trong 9 biến ảnh hưởng đến sự tham gia của cộng đồng trong du lịch, có 7 biến chủ yếu thuộc về bản thân của cộng đồng (kỹ năng, sự tự tin, nhu cầu, sở thích liên quan đển du lịch, sở hữu nghề truyền thống, cảm nhận vai trò của ngành du lịch và sự cổ vũ của gia đình), 2 biến chủ yếu liên quan đến chính quyền địa phương (khuyến khích làm du lịch, tạo co hội để người dân tham gia làm du lịch).

Sự tham gia trong du lịch của cộng đồng ở thành phố Hà Tiên có mối quan hệ đồng dấu $(+)$ với kỹ năng du lịch, sự tự tin để làm du lịch, mong muốn tham gia trong du lịch, sở thích làm du lịch, sự cổ vũ của gia đình, cơ hội tham gia du lịch, sở hữu nghề truyền thống, cảm nhận lợi thế của ngành du lịch, chính sách thu hút của địa phương. Điều này có nghĩa, 9 phương diện trên càng tốt/càng cao/càng thuận lợi/càng đúng đắn, ... thì mức độ tham gia của cộng đồng trong du lịch càng cao và ngược lại.

\section{KẾT LUẬN}

Sự tham gia của cộng đồng trong du lịch có ý nghĩa quyết định đối với sự phát triển du lịch bền vững của địa phương. Thành phố Hà Tiên là một trong những địa phương phát triển du lịch mạnh nhất ở tỉnh Kiên Giang, nhờ đó, thu hút đáng kể sự tham gia của cộng đồng trong du lịch. Sự tham gia của cộng đồng trong du lịch mang lại cho họ nhiều lợi ích trên phương diện kinh tế và xã hội. Tham gia trên cơ sở nguồn lực, thế mạnh của của gia đình/bản thân kết hợp với sự hỗ trợ của địa phương là đặc trưng cho loại hình tham gia trong du lịch của cộng động ở thành phố Hà Tiên. Kết quả nghiên cứu cho thấy có 9 nhân tố ảnh hưởng đến sự tham gia của cộng đồng trong du lịch ở địa bàn nghiên cứu. Để thu hút sự tham gia của cộng đồng trong du lịch, ngoài phát triển giáo dục, địa phương cần đẩy mạnh phát triển du lịch, thông tin rộng rãi về tầm quan trọng của ngành du lịch, đồng thời tạo điều kiện thuận lợi để người dân tham gia làm du lịch.

\section{TÀI LIẸU THAM KHẢO}

Alshboul, K. (2016). Assessing community involvement in tourism development around a proposed World Heritage Site in Jerash, Jordan (doctoral dissertation). The University of Waterloo.

Aref, F., Gill, S.S., \& Aref, F. (2010). Tourism development in local communities: As a community development approach. Journal of American Science, 6(2), 155-161.

Aref, F. (2011). Sense of community and participation for tourism development. Life Science Journal, 8(1), 20-25.

Bộ Chính trị. (2017). Nghị quyết về "phát triển du lịch trở thành ngành kinh tế mũi nhọn" (Số 08NQ/TW). https://vietnamtourism.gov.vn/index.php/docs/841

Đào Ngọc Cảnh \& Nguyễn Kim Hồng. (2017). Thực trạng và giải pháp phát triển du lịch biển - đảo thị xã Hà Tiên, tỉnh Kiên Giang. Tạp chí Khoa học Truò̀ng Đại hoc Su phạm Thành phố Hồ Chí Minh, 14(2), 128-139.

Đỗ Thiện Toàn, Bùi Văn Trịnh \& Nguyễn Quốc Nghi. (2016). Các nhân tố ảnh hưởng đến sự tham gia vào hoạt động du lịch vườn sinh thái của hộ gia đình tại huyện Phong Điền, thành phố Cần Thơ. Tạp chí Khoa học Trương Đại hoc Cần Tho, 46d, 12-19.

Eagles, P.F.J., Bowman, M. E., \& Tao, T. C.-H. (2001). Guidelines for tourism in parks and protected areas of East Asia. IUCN, Gland, Switzerland and Cambridge.

Ekwale, A.E. (2014). An assessment of local community involvement in community based ecotoursm planning and development: The case of Takamanda National Park, South West Region, Cameroon (master's thesis). Eastern Mediterranean University.

Hoàng Giám. (13/08/2019). Thành phố Hà Tiên: Đầu tu nâng cao dịch vu, sản phẩm du lịch. https://hatien.kiengiang.gov.vn/trang/TinTuc/151 /1011/TP.-HA-TIEN--dau-tu-nang-cao-dich-vu-san-pham-du-lich.html

Huy Thịnh. (01/11/2020). Kiên Giang làm mói cho du lịch Hà Tiên. https://baodautu.vn/kien-gianglam-moi-cho-du-lich-ha-tien-d132331.html

Joobi, V.P., \& Satheesh, E.K. (2017). Local community participation in responsible tourism A case of Kumarakam Panchayath in Kerala. International Journal of Current Research in Multidisciplinary, 2(11), 5-11.

Johnston, R. (2000). Community. In R. Johnston, D. Gregory, G. Pratt \& M. Watts (Eds.), The dictionary of human geography (pp. 101-102). Oxford: Blackwell.

Lê Huy Hải. (21/12/2017). Phát huy tiềm năng du lịch Hà Tiên - Bài 2: Nghe đờn ca và ngắm trăng lên trên đầm Đông Hồ. https://baotintuc.vn/dulich/phat-huy-tiem-nang-du-lich-ha-tien-bai-2- 
nghe-don-ca-va-ngam-trang-len-tren-dam-dongho-20171220100546365.htm

Mak, B.K.L. (2011). Community participation in tourism: A case study from Tai $O$, Hong Kong (master's thesis). The University of Hong Kong.

Mugizi, F., Ayorekire, J. \& Obua, J. (2017). Factors that influence local community participation in tourism in Murchison Falls Conservation Area. Journal of Environtment Science and Engineering, A6, 209-223.

Mustapha, N. A., Azman, I. \& Ibrahim, Y. (2013). Barriers to community participation in toursim development in Island Destination. Journal of Tourism, Hospitality \& Culinary Arts, 5(1), 103-124.

Nguyễn Quốc Nghi, Nguyễn Thị Bảo Châu \& Trần Ngọc Lành. (2012). Các nhân tố ảnh hưởng đến quyết định tham gia tổ chức du lịch cộng đồng của người dân ở tỉnh An Giang. Tạp chí Khoa hoc Truờng Đại hoc Cần Tho, 23b, 194-202.

Salleh, N.H.M., Shukor, M.S., Othman, R., Samdudin, M., \& Idris, S.H.M. (2016). Factors of local community participation in tourismrelated business: Case of Langkawi Island. International Journal of Social Science and Humanity, 6(8), 565-571.

Shui, W., Xu, X., Wei, Y. \& Wang, X. (2012). Influencing factors of community participation in tourism development: A case study of Xingwen World Geopark. Journal of Geography and Regional Planning, 5(7), 207-211.

Thiện Kỳ. (20/02/2019). Nét đẹp du lịch thành phố Hà Tiên. https://dulich.laodong.vn/diem-den/netdep-thanh-pho-du-lich-ha-tien 658263.html\#: :text=V\%E1\%BB\%9Bi\%20vi\% $\mathrm{E} 1 \% \mathrm{BB} \% 87 \mathrm{c} \% 20 \% \mathrm{C} 4 \% 91 \% \mathrm{C} 3 \% \mathrm{~B} 3 \mathrm{n} \% 20 \mathrm{tr} \% \mathrm{C}$ $3 \%$ AAn $\% 202$, (ch\%E1\%BB\%89\%20sau\%20Ph $\% \mathrm{C} 3 \% \mathrm{BA} \% 20 \mathrm{Qu} \% \mathrm{E} 1 \% \mathrm{BB} \% 91 \mathrm{c}$

Trần Đức Thanh. (2003). Nhập môn khoa hoc du lịch. Hà Nội: Nxb Đại học Quốc gia Hà Nội.

Việt Tiến. (19/08/2018). Hà Tiên trước co hội lón. https://nhandan.com.vn/tin-tuc-kinh-te/ha-tientruoc-co-hoi-lon-332878/ 